\title{
UMA POLITICA DE CERTIFICAÇÃO PROFISSIONAL ORIENTADA PARA A INCLUSÃO SOCIAL
}

\author{
Silvia Maria Manfredi*
}

\section{Resumo}

O artigo contém a reconstrução e análise das experiências recentes levadas a efeito pelo Departamento de Certificação e Orientação Profissional da Secretaria de Políticas Públicas de Emprego do Ministério do Trabalho e Emprego - MTE/2003-2007, voltadas para a construção de políticas inclusivas de qualificação, certificação e orientação profissional. O modelo de certificação profissional desenvolvido foi construído de forma participativa e negociada. Conceitualmente, pretende ser um contraponto a algumas orientações hegemônicas. Do ponto de vista jurídico-institucional visou à construção do Sistema Nacional de Certificação Profissional. O projeto pautou-se numa perspectiva inclusiva, pois pretendia ser, além de um mecanismo de credenciamento para o trabalho, uma passarela de ingresso / retorno ao sistema escolar formal ou de inserção em percursos formativos de natureza continuada. O modelo elaborado foi testado com duas categorias profissionais e tais experiências-piloto também são retratadas no presente artigo.

Palavras-chave: Trabalho. Educação. Qualificação. Certificação profissional. Políticas públicas.

\section{Introdução}

A construção de políticas de certificação profissional vem sendo ensaiada no Brasil há mais de 15 anos, pelas diferentes gestões governamentais, em nível federal. Diversos modelos e concepções vêm sendo debatidas, enfrentando polêmicas de diversas ordens - conceituais e institucionais. Os embates conceituais envolvem a definição e a escolha de uma das orientações teórico-

\footnotetext{
* Doutora pela Universidade de São Paulo (1983), com Pós-Doutoramento na Università Degli Studi di Brescia, Itália (1993). Professora Livre-Docente Aposentada da Faculdade de Educação da Universidade Estadual de Campinas (silmanf@hotmail.com).
} 
metodológicas de certificação profissional, entre as varias existentes, pois cada uma delas conduz à construção de referenciais, critérios e procedimentos metodológico-operacionais distintos. No que diz respeito à dimensão institucional, há que se considerarem questões de natureza jurídico-legais, políticoideológicas, técnico-operacionais e financeiras. Além disso, a proposição de políticas públicas de certificação profissional requer o envolvimento dos diferentes atores sociais afeitos à questão, bem como a edificação de uma estratégia de debate e implantação que, além de orientar-se por uma concepção de certificação/ qualificação sócio-profissional, inclua a participação dos diferentes atores interessados - trabalhadores, empresários e entidades governamentais e da sociedade civil.

Todos esses desafios foram retomados pelos ministérios da educação e do trabalho, durante a gestão do Governo Lula (2002-2007). Neste artigo, pretendemos fazer uma analise das experiências recentes levadas a efeito pelo Departamento de Certificação e Orientação Profissional da Secretaria de Políticas Públicas de Emprego do MTE/2003-2007, voltadas para a construção de políticas inclusivas de qualificação, certificação e orientação profissional,

articuladas entre si e inseridas no Sistema Público de Emprego. A despeito dos avanços e recuos, algumas ações foram inovadoras e significativas, por isso merecem, a nosso ver, ser divulgadas e avaliadas publicamente. Iniciemos pela cronologia das ações e iniciativas realizadas.

\section{Relembrando os passos empreendidos}

A certificação profissional vinha sendo objeto de discussão no Ministério do Trabalho e Emprego - MTE, em parceria com a OIT, desde a gestão de 1997 a 2001, através do projeto CERT/DV - SEFOR/MTE-OIT. Em seus quatro anos de desenvolvimento, o projeto estimulou a realização de seminários e reuniões com os responsáveis pelo desenvolvimento de várias experiências de certificação, tanto do setor privado, como do setor publico. Por outro lado, o direito à certificação, previsto na LDB (Lei 9.394/96) veio a ser reforçado pelo Decreto 2.208/97, artigo $3^{\circ}$ e Portaria 646/97 (ambos promulgados pelo MEC).

Na gestão do Governo Lula, com a formulação do PNQ (2003), PNQSP (2004-2007) e dos documentos produzidos pela Secretaria de Educação Profissional e Tecnológica/ SETEC - MEC, houve uma redefinição das orientações e premissas que iriam orientar as políticas de qualificação, certificação e orientação profissional. Nesse sentido, em janeiro de 2003, o então secretario da Semtec (atual Setec) retirou do Conselho Nacional de Educação a proposta de criação do Sistema de Certificação Profissional baseado no modelo de competências, designado SNCCP, que fora enviada em dezembro 
de 2002. A partir da criação da Comissão Interministerial de Certificação Profissional - CICP (portaria n. 14/04), o MEC - Setec e MTE passam a coordenar o debate e a elaboração da nova proposta.

O Programa de Qualificação Social e Profissional - PQSP, coordenado pelo Departamento de Qualificação da Secretaria de Políticas Públicas de Emprego do Ministério do Trabalho e Emprego, formulado em sintonia com o Plano Plurianual - PPA, versão 2004-2007, orienta-se pelos seus "megaobjetivos": a) "inclusão social e redução das desigualdades sociais"; b) "crescimento com geração de trabalho, emprego e renda, ambientalmente sustentável e redutor das desigualdades regionais"; c) "promoção e expansão da cidadania e fortalecimento da democracia" (MTE, 2003, p. 9) ${ }^{1}$.

Nessa perspectiva, as políticas de qualificação, certificação e orientação profissional são assumidas como direito social e devem:

a) ser articuladas entre si e aos sistemas públicos: de emprego e de educação;

b) sustentar-se na participação e na concertação social.

\section{Delineando uma perspectiva inclusiva de qualificação e certificação}

A qualificação profissional, entendida como direito social, refere-se ao direito de acesso a oportunidades de educação permanente, tanto no âmbito da qualificação profissional, como no âmbito da educação escolar de nível básico (fundamental e médio). Quando se refere à certificação, tal direito ancora-se na idéia de inclusão e de igualdade de oportunidades de acesso à educação escolar, às possibilidades de obtenção de emprego ou de aferição de renda através do trabalho. Nessa perspectiva, a institucionalização da certificação é concebida como mecanismo que garante o reconhecimento social das experiências e conhecimentos do/a trabalhador/a, acumulados a partir de sua trajetória de vida, trabalho e participação social e política.

Essa orientação incorpora os princípios da valorização do trabalho, contidas nas Recomendações 195 da OIT, quando se refere à formação contínua e às "aprendizagens (formais, informais) realizadas ao longo da vida, com a finalidade de desenvolver competências e qualificação" e que podem ser reconhecidas e certificadas para fins profissionais.

A certificação profissional, diferentemente da certificação ocupacional, foi entendida pelos gestores dessa secretaria como uma subfunção da qualificação social e profissional, cujo propósito é promover o reconhecimento social dos conhecimentos do trabalhador/a, adquiridos fora dos processos formais de aprendizagem.

1. Ver Documento do Plano Nacional de Qualificação (2003-2007), Ministério do Trabalho e Emprego, p. 9. 
Essa visão está assim expressa nos documentos oficiais:

Tradicionalmente, o/a trabalhador/a que atua em determinada ocupação e, em decorrência de déficit educacional ou ausência de oportunidades formativas, domina precariamente a linguagem e os recursos técnico-tecnológicos de sua ocupação, tende a ser classificado como desqualificado. Nesse sentido, seu estatuto de pertencimento à estrutura ocupacional caracterizar-se-á pela negatividade e pela ausência, por aquilo que não é. Por meio das discussões introduzidas por uma leitura progressista dos processos de certificação, o reconhecimento da experiência adquirida por meio das experiências de vida e de trabalho (os chamados processos formativos informais) permite afirmar que o/a trabalhador/a que não domina os códigos simbólicos hegemônicos é igualmente dotado de um saber, construído ao longo de sua existência, cuja riqueza simbólica e prática não podem ser previamente desprezadas tão somente em virtude de ser diferente dos códigos hegemônicos. Esse/a trabalhador/a possui o direito ao reconhecimento de seu saber prático, no sentido da construção de procedimentos e instituições que viabilizem seu diálogo com os códigos dominantes, a afirmação de sua eventual eficácia socio-econômica e a adequada inserção sócio-ocupacional e educacional dos grupos secularmente excluídos (SOUSA, 2004, p. 2).

Trata-se de uma forma de reconhecimento vinculada a processos de fortalecimento da cidadania, visto que o sistema de certificação pode vir a ser, além de um mecanismo de credenciamento para o trabalho, uma passarela de ingresso/ retorno ao sistema escolar formal ou de inserção em percursos formativos de natureza continuada. A visão da certificação como uma subfunção da qualificação profissional e expressa como um direito impulsionou a elaboração de uma série de documentos, debates, publicações sobre as experiências internacionais de qualificação, bem como a necessidade de integrá-la ao Sistema Público de Emprego. Tais produções e debates propiciaram um avanço conceitual que foi incorporado no projeto de lei que criaria o Sistema Nacional de Certificação Profissional e nos referenciais conceituais e metodológicos que serviram de parâmetro para o desenvolvimento das experiências-piloto, nas áreas de construção civil e metal-mecânica.

\section{Iniciativas visando à articulação com os demais sistemas e políticas sociais}

A partir de 2003, o Ministério do Trabalho e Emprego desenvolveu esforços em conjunto com diversos agentes governamentais e sociais, com vistas a estruturar institucionalmente a certificação profissional como uma função do Sistema Público de Emprego, em articulação com o Sistema Nacional de 
Educação. Para tanto, foi constituído Grupo de Trabalho Interministerial, pela Portaria Interministerial n. 13, de 02 de setembro de 2003, composto pelos Ministérios do Trabalho e Emprego, da Educação, do Desenvolvimento, Indústria e Comércio Exterior, da Saúde e do Turismo, além dos Conselhos Nacionais da Educação e do Trabalho.

A Comissão Interministerial de Certificação Profissional foi criada pela Portaria Interministerial n. 24, de 20/12/2004, tendo como objetivos:

a) subsidiar a elaboração de uma Política Nacional de Certificação Profissional, por meio da elaboração de um diagnóstico das propostas e experiências existentes na área da certificação profissional;

b) propor e realizar estudos de casos ou projetos pilotos estratégicos de distintas complexidades;

c) apresentar proposta estruturada de institucionalização de uma política nacional de certificação profissional, no prazo de dez meses, a contar de sua constituição;

d) propor metodologia de ampla consulta pública aos vários segmentos sociais envolvidos no tema.

Essa Comissão Interministerial fez várias reuniões durante os anos 2004/ 2005, para elaborar uma minuta com uma proposta institucional de construção do Sistema Nacional de Certificação Profissional. Tal proposta foi submetida à discussão e ultimada, após várias consultas feitas aos segmentos da sociedade civil: entidades educacionais, entidades representativas dos trabalhadores, empresários, empresas, conselhos profissionais, entidades certificadoras e instituições de pesquisa; setores da administração governamental: departamentos e secretarias dos vários ministérios afeitos à temática: educação, saúde, ciências e tecnologia, desenvolvimento, turismo, entre outros através de audiências públicas ${ }^{2}$. Para concluir o debate público foi realizado um Seminário Internacional, que contou com a participação de vários especialistas europeus e latino-americanos que contribuíram para aprofundar a temática e trazer novos subsídios.

Ao final do processo, com base nas sugestões e discussões, concluiu-se a redação de um desenho de Decreto-Lei, encaminhado à Casa Civil, que continha os elementos para a institucionalização do Sistema Nacional de Certificação Profissional. Tal projeto tinha por conteúdo: 1 . finalidades e princípios do sistema; 2. concepção de certificação; 3 . finalidades, competências, composição da Comissão Nacional de Certificação Profissional (CNCP); 4. finalidades e competências da Secretaria Executiva da CNCP, das Comissões Técnicas Setoriais, Organismos de Certificação; 5. Repertório Nacional de Qualificações

2. A minuta do Decreto-Lei de criação do Sistema Nacional de Certificação de Profissional foi concluída enviada à Casa Civil no final de 2007, mas não foi regulamentada. 
Certificáveis - bases normativas e conceituais; 6 . articulação entre certificação profissional, itinerários formativos e equivalência com a educação profissional; 7. financiamento da certificação profissional.

O projeto foi construído em conjunto com todas as instâncias governamentais que já possuem iniciativas de certificação e constituiu um passo no sentido da criação de normas jurídico-institucionais e competências para a viabilização da certificação / orientação profissional em nível sistêmico, nacional e regulado por lei. Ainda que o projeto não tenha sido sancionado, constituiu uma iniciativa que caminhou no sentido de construir um sistema nacional de certificação profissional, ainda inexistente no Brasil.

\section{Iniciativas com vistas à construção coletiva e negociada das políticas de qualificação e certificação}

No Planfor, através da Sefor (gestão 1998-2002), já se havia iniciado o processo de interlocução e consulta com os agentes sociais, estimulando sua participação nos fóruns coletivos e institucionais de discussão da política de formação profissional. A criação das Comissões Estaduais e Municipais de Trabalho foi um primeiro passo para envolver a sociedade civil no processo na elaboração, fiscalização e condução das políticas públicas de qualificação.

Contudo, segundo algumas avaliações realizadas, tais comissões ainda possuem uma serie de fragilidades no plano da representação política e participação democrática. Com o intuito de possibilitar que tais comissões exercessem um papel mais ativo, critico e propositivo, o PQSP estimula a construção de fóruns e mecanismos de negociação da qualificação profissional nesses e em outros espaços e programas. Através da criação de Comissões de Concertação no interior dos Planseqs (Planos Setoriais de Qualificação) e do Grupo de Acompanhamento das experiências-piloto de certificação profissional, entendeu-se aos sujeitos protagonistas do processo - empresários, trabalhadores, gestores, educadores - o direito de definir os objetivos, conteúdos, métodos dos planos de qualificação, bem como a escolha das qualificações que deveriam ser objeto de certificação. Através da participação e concertação procurou-se incentivar a intervenção de sujeitos-cidadãos, heterogêneos, na formulação, planejamento, avaliação e controle das políticas públicas de qualificação e certificação. No âmbito da certificação profissional, foi criado um Grupo de Acompanhamento para duas experiências-piloto: uma no setor de construção civil e outra do setor metal-mecânico (setor automotivo). O grupo foi constituído por representações de trabalhadores, empresários, organismos técnicos e governamentais relacionados ao setor. O grupo acompanhou, mediante debates e negociações, o desenvolvimento de todas as ações previstas 
para efetivar, nos setores supramencionados, a certificação das ocupações escolhidas: a de pedreiro (na construção civil) e a de preparador e operador de máquinas (no setor automobilístico).

O processo de certificação profissional que se efetivou nesses dois setores, ao mesmo tempo em que formalizou o reconhecimento da qualificação para o trabalho, encaminhou e orientou os trabalhadores que participaram das experiências-piloto para: oportunidades de reingresso e continuidade no sistema de ensino, ou para a inserção em programas de formação profissional inicial e continuada, segundo os itinerários formativos definidos pelo Decreto 5.154, de 23 de julho de $2004^{3}$.

Tratou-se, portanto, de um processo de certificação para fins profissionais e escolares, respaldado em dispositivos legais criados para tais fins:

a) o Parecer CNE/CEB 40/2004 aprovado em 8/12/2004, que trata das normas para execução de avaliação, reconhecimento e certificação de estudos previstos no artigo 41 da Lei 9.394/96 (LDB);

b) o Decreto 5.478, de 24 de junho de 2005, que institui, no âmbito das instituições federais de educação tecnológica, o Programa de Integração da Educação Profissional ao Ensino Médio na Modalidade de Educação de Jovens e Adultos - Proeja ${ }^{4}$.

Além disso, o processo de certificação, desenvolvido nas duas experiênciaspiloto acima mencionadas também articulou a certificação e a formação com ações de acompanhamento, orientação e inserção no mundo do trabalho, pois o centro de referência local de oferta de qualificação profissional inicial e continuada escolhido atuava junto a um centro de encaminhamento e orientação para o trabalho. Caminhou-se, assim, no sentido de construir os Centros Públicos de Emprego, Trabalho e Renda, que têm por objetivo oferecer aos trabalhadores / as um atendimento integrado entre: habilitação para o segurodesemprego, encaminhamento para a certificação, qualificação social e profissional e oportunidades de emprego ou de geração de renda. As duas experiências-piloto que serão tratadas de forma mais detalhada, num item à parte, representaram uma tentativa de operacionalizar as premissas e orientações conceituais da proposta oficial. Revelaram-se um terreno fértil de avaliação

3. O Decreto 5.154, de 23 de julho de 2004, em seu artigo $3^{\circ}$, parágrafos $1^{\circ}$ e $2^{\circ}$ considera "itinerário formativo o conjunto de etapas que compõem a organização da educação profissional em uma determinada área, possibilitando o aproveitamento contínuo e articulado dos estudos". A articulação far-se-á "preferencialmente, com os cursos de educação de jovens e adultos, objetivando a qualificação para o trabalho e a elevação do nível de escolaridade do trabalhador, o qual, após a conclusão com aproveitamento dos referidos cursos, fará jus a certificados de formação inicial ou continuada para o trabalho".

4. O artigo $7^{\circ}$, Decreto 5.478, de 24 de junho de 2005, garante às instituições federais de educação tecnológica "[...] a possibilidade de aferir e reconhecer, mediante avaliação individual, conhecimentos e habilidades obtidas em processos formativos extra-escolares". 
e verificação das potencialidades teórico-metodológicas da concepção discutida e proposta, contribuindo, também, para dar um input à participação coletiva e negociada das ações de certificação profissional. Como se verá, os resultados foram positivos e factíveis, ainda que pontuais e limitados.

\section{A escolha de um referencial conceitual baseado na noção de qualificação social e profissional, como alternativa ao de modelo de competências}

Como salientamos no início, a opção por um tipo de abordagem de qualificação profissional nos leva a escolher uma determinada concepção de certificação e, consequentemente, diversos percursos e procedimentos metodológicos. Existe um nexo teórico-metodológico entre concepções, metodologias e instrumentos de certificação. Esses três elementos devem ser congruentes entre si, e não escolhidos ao acaso ou por conveniência.

No caso especifico da certificação profissional, a questão conceitual a enfrentar é o que se entende por competência ou expertise profissional e qual é sua relação com a qualificação para e no trabalho. Existem várias orientações teóricas que referenciam as noções de qualificação para e no trabalho: a concepção derivada do modelo job/skills; a orientada para o modelo de competências, a interacionista (MANFREDI, 2007) e a concepção denominada nos documentos do MTE de qualificação social e profissional.

Na concepção derivada do modelo job/skills, os parâmetros para a qualificação profissional são estabelecidos a partir das tarefas, cargos, funções inerentes ao processo de organização do trabalho. Assim, a caracterização do perfil profissional e as competências a ele agregadas (conhecimentos, habilidades, procedimentos técnicos, atitudes, domínio de instrumentos etc.) são determinadas pelas características do posto de trabalho e previstas nas normas organizacionais da empresa (nos manuais de rotina de trabalho e de cargos e salários). Na ótica desse modelo, a qualificação é concebida como sendo "adstrita" ao posto de trabalho, e não como um conjunto de atributos inerentes ao trabalhador. Há, portanto, na lógica dessa concepção de qualificação uma definição explícita e circunscrita do perfil técnico-profissional almejado: as competências profissionais são prescritas, estabelecidas a partir de Standards técnicos definidos a partir do posto de trabalho, de normas e procedimentos padronizados. Sua aferição, em geral, se operacionaliza tomando como pontos de referência padrões de desempenho e de domínio de conhecimentos técnicos e gerais correspondentes aos perfis previamente traçados, através de procedimentos e instrumentos que permitem mensurar de maneira objetiva e fidedigna os atributos do trabalhador qualificado. Privilegiam e utilizam métodos diretos e procedimentos quantitativos nas práticas de avaliação e certificação. 
A perspectiva interacionista considera a qualificação profissional como resultante de processos psicológicos e sociais próprios da interação sujeitoorganização, ou contexto organizacional. Nesse caso ela é vista como o conjunto de estratégias cognitivo-comportamentais de que o trabalhador (a) dispõe para responder às solicitações dos contextos de trabalho e, simultaneamente, como um conjunto de conhecimentos, representações, expectativas e idéias sobre si mesmo, desenvolvidas nas interações vivenciadas nos contextos organizacionais. Essa concepção demarca o caráter dinâmico das competências profissionais, a importância do enfrentamento social na sua construção e sua forte relação com o contexto em que é desenvolvida.

O modelo de competências, por sua vez, tende a centrar o foco da qualificação sobre o sujeito do trabalhador (considerado individual e isoladamente), interpretando-a como um conjunto de atributos (de natureza psicossocial) e aquisições pessoais, fruto de êxitos e de investimento individual, adquiridos formalmente (através de cursos / treinamentos) e/ ou por meio da experiência profissional, independentemente do posto de trabalho, dos contextos organizativo e sociocultural. Trata-se de potencialidades e capacidades que um indivíduo possui e que, portanto, podem ser transferidas para qualquer situação ou contexto de trabalho. Tais potencialidades individuais são vistas, menos como um "estoque de conhecimentos/habilidades", mas sobretudo como capacidades de agir , intervir, decidir em situações nem sempre previstas ou previsíveis. O exercício dessa capacidade implicaria a mobilização de competências adquiridas ou construídas mediante aprendizagem, no decurso da vida ativa, tanto em situações de trabalho como fora deste, reunindo:

a) o "saber fazer", que recobre dimensões práticas, técnicas e científicas, adquirido formalmente (cursos / treinamentos) e/ ou por meio da experiência profissional;

b) o "saber ser", incluindo traços de personalidade e caráter, que ditam os comportamentos nas relações sociais de trabalho, como: capacidade de iniciativa, comunicação, disponibilidade para a inovação e mudança, assimilação de novos valores de qualidade, produtividade e competitividade;

c) o "saber agir", subjacente à exigência de intervenção ou decisão diante de eventos - exemplos: saber trabalhar em equipe, ser capaz de resolver problemas e realizar trabalhos novos, diversificados.

Esse enfoque de qualificação postula a certificação como uma prática que possibilita identificar e avaliar o conjunto de "saberes e competências" (mensuráveis e classificáveis) de que um trabalhador é portador, centrando o foco do balanço de competências muito mais nos resultados do que no processo.

Contrapondo-se às orientações anteriores, no PQSP, atribui-se à noção de qualificação uma dimensão de construção social de natureza histórica e dinâmica, 
que se configura a partir de uma teia complexa de determinações e relações. Uma construção que constitui uma mediação entre o trabalho e as aprendizagens subjetivas e técnicas necessárias para sua realização, que se configuram a partir das bases materiais e socioculturais da organização do trabalho em nossa sociedade. Como conceito histórico-concreto de mediação das relações trabalho-educação, envolve as múltiplas tensões inerentes: a) às relações, interesses e motivações conflitivas no âmbito das relações de trabalho inter (capital e trabalhadores), intra (diferentes segmentos dos trabalhadores como engenheiros, técnicos e peões) e extra (cortes por gênero, etnia, geração etc.) classes sociais; b) à construção das classificações, categorização e credenciamento das capacidades, conhecimentos e habilidades necessárias para exercer determinada atividade de trabalho; c) à influência do costume, da tradição, da força e da capacidade de barganha das organizações ou coletivos auto-identificados por direitos ou trajetórias profissionais; e, por último, d) aos padrões de regulação formal e institucionalizada dos requisitos e conteúdos necessários ao exercício e desenvolvimento de atividades profissionais.

Assim concebida, a noção de qualificação passa a ser apreendida como uma construção balizada por parâmetros socioculturais e históricos, na qual o trabalho constitui uma relação social e os espaços de trabalho, instâncias de embates, conflitos e formação. Uma noção que considera tanto as condições objetivas de trabalho como a disposição subjetiva por meio da quais os trabalhadores coletivos, como sujeitos ativos, constroem e reconstroem sua profissionalidade. A qualificação individual é, ao mesmo tempo, pressuposto e resultado de um processo de qualificação coletivo, condicionado pela/na organização da produção social e dos confrontos e negociações entre as forças que intervêm nesse processo - capital e trabalho. O grau de complexidade em que se expressa a qualificação individual depende das possibilidades de potenciação dos tipos de trabalho conhecidos na sociedade. Esse é o motivo pelo qual a qualificação profissional do trabalhador não pode ser considerada a demonstração prática de competências individuais.

Com base nesses pressupostos epistemológicos e políticos, resgata-se a centralidade e a importância do trabalho, dos sujeitos que trabalham. Tratase de uma concepção de qualificação profissional alternativa àquelas que privilegiam perspectivas individualizantes ancoradas, tão somente, nas exigências dos postos / mercado de trabalho, ou de competências resultantes de processos de aprendizagem individuais. 


\section{Construindo e testando um novo modelo inspirado nos conceitos de aprendizagem (formal e não formal): A Experiência Piloto de Certificação realizada durante 2006, em convênio com a Fundação Florestan Fernandes - Diadema - SP}

Com base na concepção de qualificação social e profissional acima descrita e nas premissas de diálogo e negociação social na construção de políticas públicas, estruturou-se um percurso de certificação que garantisse:

a) a efetiva participação dos interlocutores sociais - sindicatos, instituições educacionais e dos setores educacionais e gestores públicos -, na produção dos referenciais de certificação, definindo: os perfis profissionais, as bases metodológicas e operações do processo de avaliação, os procedimentos formais de certificação e sua articulação com os percursos de formação escolar e profissional (para fins de complementação e ou continuidade);

b) a preparação dos profissionais que atuariam no processo de certificação profissional - educadores, especialistas em avaliação, instrutores de educação profissional e observadores (representantes de trabalhadores e de empresários, dos ministérios da educação);

c) a adesão dos trabalhadores candidatos à certificação, através de uma campanha de divulgação e de atividades de sensibilização sobre as finalidades e instrumentos de certificação a serem utilizados.

\section{Participação dos diferentes interlocutores sociais}

A Experiência Piloto de Certificação contou com a participação de: representantes dos trabalhadores e empresários (sindicatos dos setores - construção civil e metal-mecânico (automobilístico) - Sindicato dos Metalúrgicos de São Bernardo e Diadema, CUT, Dieese, Ciee/SP, Senai; entidades educacionais: ETE (Professores da Escola Técnica do Sistema Paula Souza), representantes do Cefet - São Paulo, mais equipe interna da Fundação e representante da Secretaria Municipal de Educação do Município de Diadema, com a supervisão de assessores dos Ministérios da Educação e do Trabalho e Emprego.

Coube ao Gaep - Grupo de Acompanhamento da Experiência Piloto, partindo da proposta de certificação definida do Sistema Nacional de Certificação, elaborar o desenho da experiência: redigir o documento referente à caracterização dos perfis profissionais a serem certificados; acompanhar a elaboração e aplicação dos instrumentos, bem como avaliar o andamento do projeto-piloto. 


\section{Os certificadores e a construção do processo de avaliação diagnóstica para fins de certificação}

A equipe de certificadores foi constituída de especialistas em avaliação, educação de jovens e adultos e instrutores / professores de educação profissional da Fundação Florestan Fernandes.

A preparação das ações foi feita junto com o GAEP e através de uma oficina de formação efetuada por assessores do MTE, responsáveis pelo andamento do projeto. Em seguida, a equipe planejou, desenvolveu os instrumentos e os procedimentos de certificação e sua aplicação. Todo o processo envolveu uma interlocução com os componentes do Gaep e com os assessores ministeriais.

A metodologia de elaboração dos perfis e itinerários profissionais foi feita com base na:

a) descrição da atividade de trabalho e os respectivos atributos/capacidades necessárias para realizá-la;

b) escolha dos perfis profissionais: $\mathrm{CBO}$ - Classificação Brasileira de Ocupações; áreas profissionais definidas nas Diretrizes Curriculares Nacionais da Educação Profissional - DCNEP e CNAE - Classificação Nacional de Atividades Econômicas, e com base nas situações e condições de trabalho no território;

c) definição das seguintes categorias de análise para estabelecer a qualificação social e profissional correspondente a cada perfil profissional: c1 conhecimentos teóricos e práticos; c2 - métodos e procedimentos de trabalho. c3 - nível de escolaridade; c4 - planejamento do trabalho; c5 cuidados com a saúde e meio ambiente; c6 - noções de gestão;

d) estabelecimento de referenciais e critérios de certificação;

e) estabelecimento de critérios de complementação e equivalência com os percursos escolares (de educação escolar regular e profissional).

\section{A construção dos instrumentos de avaliação para fins de certificação}

Quanto aos procedimentos e instrumentos, construiu-se um conjunto de passos e materiais ajustáveis ao nível de letramento, escolaridade, cultura, regionalidade e condições socioeconômicas dos candidatos, compostos por: roteiros de entrevista semi-estruturados e estruturados, roteiros de observação; roteiros de atividades de grupo, provas praticas e teóricas de conhecimentos, aptidões e habilidades, para identificar e avaliar o desempenho profissional.

O processo de certificação, com premissas de inclusão, deve atender a todo aquele que se candidate. Nesse sentido, para dar conta da diversidade de 
candidatos, elaboraram-se procedimentos e instrumentos de avaliação diagnóstica que atendessem aos objetivos e finalidades da certificação, mas que levaram em consideração as características socioculturais dos sujeitos a serem avaliados. Entendeu-se ser necessária a adoção de diversos procedimentos para auxiliar o candidato a reconhecer, em sua experiência, as habilidades e saberes adquiridos em sua trajetória de profissional e de vida. Em vista disso, optou-se pelo uso de procedimentos e instrumentos variados que servissem para diagnosticar as diferentes dimensões: cognitivas, técnico-instrumentais, psicossociais e culturais dos sujeitos a serem avaliados, a serem ministrados de forma individual e coletiva. Os coletivos reúnem uma série de técnicas e instrumentos de trabalho em grupo que foram utilizados para criar, no inicio do processo, um pequeno coletivo de certificação que permitiu que cada candidato se inteirasse do processo e se integrasse no interior do grupo de participantes.

Para cada candidato foi construído um dossiê ou portfolio, com toda a documentação obtida, para que o processo ficasse registrado e arquivado na entidade certificadora oficial, o Cefet-SP. O envolvimento e a participação dos trabalhadores candidatos partiram de uma adesão voluntária e opcional.

Subjetivamente, toda a situação de avaliação mobiliza sentimentos e representações relacionadas com a auto-imagem e a auto-estima. Nesse sentido, o processo de certificação tem que ser opcional e consciente. Ou seja, é preciso que o sujeito que se submeta a um processo de certificação saiba com que finalidade e como será avaliado, para poder escolher se deseja inserir-se ou não, e a partir dessa opção ter uma participação ativa e consciente. O envolvimento num processo de avaliação em que se utilizam procedimentos diagnósticos que propiciam momentos de reflexão pode contribuir para gerar escolhas e opções mais conscientes e uma maior clareza sobre as respectivas potencialidades e limites individuais. Nesse sentido, o procedimento de avaliação diagnóstica pode e deve ser reveladora e consistente, mas ao mesmo tempo conscientizadora e problematizante.

Com essa perspectiva, o processo de avaliação para fins de certificação foi precedido de todo um trabalho de sensibilização dos participantes, para que estes se apropriassem do sentido e da orientação que seriam dados ao processo, fazendo com que os momentos de avaliação fossem ocasiões para refletirem sobre suas historias pessoais, suas trajetórias profissionais e sociais. O momento inicial do processo consistiu, portanto, num momento coletivo para inteirar e sensibilizar os candidatos sobre a natureza do processo ao qual iriam se integrar, esclarecendo sua finalidade, tempos, procedimentos, entre outros. Além disso, por se tratar de uma orientação com foco na inclusão, a perspectiva de continuidade do processo formativo e a motivação para a 
efetivação dependeriam de escolhas, motivações e compromissos a serem assumidos, individualmente por cada um dos sujeitos. Entendeu-se que um processo de certificação constitui, em ultima instância, um processo de avaliação/auto-avaliação, que mobiliza sentimentos, representações, motivações, que devem ser respeitadas e acolhidas. Para um trabalhador empregado, que possui um contrato de trabalho, a obtenção de um resultado positivo ou negativo pode vir a afetar a continuidade de sua vida laboral; portanto, há que ser um processo que necessita de uma discrição quanto ao processo e aos resultados. Além do que a participação do trabalhador tem que se efetivar através de uma negociação mediada pelos representantes sindicais.

Através de atividades de avaliação individuais e / ou coletivas foi possível diagnosticar e identificar o domínio, por parte dos candidatos, de alguns conhecimentos escolares presentes no cotidiano de vida e trabalho dos trabalhadores que, raramente, são reconhecidos pelo próprio candidato ou pela instituição escolar.

Para avaliar a atuação e o desempenho na execução de tarefas próprias do setor (construção civil e metal mecânica), construíram-se vários instrumentos individualizados, tais como: simulação de tarefas através de provas práticas, roteiros estruturados de entrevista e de observação, atividade avaliativa para identificar o nível de escolaridade.

A opção pela execução de tarefa se justificou pela característica do público atendido e pelo perfil sócio-profissional escolhido. Para isso, optou-se pela realização de três atividades práticas que permitissem a observação do candidato e com isso avaliar seu domínio teórico e prático dos conhecimentos e habilidades. A entrevista estruturada teve como função esclarecer eventuais problemas ocorridos na observação das atividades práticas, bem como identificar e captar outras informações e elementos não verificáveis durante a execução das atividades.

Os instrumentos, o desempenho nas tarefas, constatações, observações obtidas para cada candidato foram anotadas, registradas e incluídas numa pasta, de modo a possibilitar a fidedignidade do andamento do processo e a comprovação formal e objetiva do julgamento efetuado.

\section{Etapas e momentos do processo}

Etapas do processo de certificação:

Momento Inicial - Etapa que antecedeu o processo de inscrição, onde foi explanado o processo e formalizada a adesão à Experiência Piloto. Nessa etapa, organizaram-se os grupos para as atividades de natureza coletiva. 
$1^{\circ}$ e $2^{\circ}$ Encontros: (duração de 2 à $2 \mathrm{~h} 30 \mathrm{~min}$ ): nesses dois primeiros encontros, desenvolveram-se atividades que permitiram aos trabalhadores identificar os saberes e as experiências adquiridas no/ pelo trabalho. Construíram-se junto com eles as noções de: habilidade, auto-avaliação, explicitando-lhes em que consiste uma avaliação de habilidades e conhecimentos necessários para a certificação. A atividade também propiciou que cada candidato fizesse uma auto-avaliação de suas capacidades em função do perfil esperado.

$3^{\circ}$ Encontro: Explicitação aos candidatos dos referenciais, critérios e procedimentos a serem adotados para a Certificação. Nesse encontro aplicou-se o instrumento de diagnóstico da escolarização. Após esse encontro, os educadores que aplicaram os instrumentos elaboraram um pequeno relatório de cada candidato para encaminhar à equipe de instrutores que iria avaliar as tarefas e o desempenho profissional.

$4^{\circ}$ e $5^{\circ}$ Encontros: Reservados à execução das tarefas específicas. A participação dos encontros foi previamente agendada. No caso das provas práticas do setor de metal-mecânico (certificação de preparadores e operadores de máquinas), as provas práticas foram feitas no local de trabalho, mediante negociação com os empregadores.

Elaborou-se um guia de orientação para os avaliadores (educadores e instrutores), sistematizando procedimentos, instrumentos e critérios para cada atividade e/ ou tarefa.

Concluído o processo, foi feita uma entrevista de devolução com cada um dos candidatos, dando-lhe um feedback de sua atuação, apontando: pontos fortes, possibilidades, limites e lacunas a serem sanadas. A documentação foi em seguida encaminhada para a agência certificadora, no caso o Cefet-SP, para o devido registro e adoção dos procedimentos cabíveis para a emissão do certificado oficial.

Todo o material também foi disponibilizado aos representantes do Gaep, tendo sido arquivada uma cópia dos processos na própria Fundação, para que possa dar prosseguimento aos trabalhos de orientação, no que se refere à continuidade da formação profissional e/ou da complementação da escolaridade básica. 


\section{Resultados - Síntese de alguns dos principais resultados}

Tabela 1. Trabalhadores envolvidos e certificados durante a Experiência Piloto de 2006.

\begin{tabular}{|l|c|c|c|c|}
\hline Trabalhadores envolvidos & \multicolumn{2}{|c|}{$\begin{array}{c}\text { Setor de Construção Civil } \\
\text { No. } \%\end{array}$} & \multicolumn{2}{c|}{$\begin{array}{c}\text { Setor M etal Mecânico } \\
\text { No. \% }\end{array}$} \\
\hline Inscritos & 80. & 100,0 & 139 & 100,0 \\
\hline Participantes & 75 & 93,75 & 125 & 89,9 \\
\hline Desistentes & 01 & 1,3 & 05 & 3,6 \\
\hline $\begin{array}{l}\text { Não completaram 0 } \\
\text { processo de avaliação }\end{array}$ & 04 & 5,1 & 09 & 6,5 \\
\hline Certificados & 41 & 54,6 & 33 & 26,4 \\
\hline $\begin{array}{l}\text { Não certificados ou } \\
\text { certificados parcialmente }\end{array}$ & 34 & 45,3 & 92 & 73,6 \\
\hline $\begin{array}{l}\text { Encaminhados para } \\
\text { cursos de complementação de } \\
\text { escolaridade formal }\end{array}$ & 45 & 60,0 & 24 & 19,2 \\
\hline $\begin{array}{l}\text { Encaminhados para a } \\
\text { complementação da qualificação sócio- } \\
\text { profissional em cursos da fundação } \\
\text { ou a serem realizados nas empresas }\end{array}$ & 34 & 45,3 & 92 & 73,6 \\
\hline Empresas envolvidas & 01 & 05 & & \\
\hline
\end{tabular}

Fonte: Fundação Florestan Fernandes - Diadema - SP

\section{Relação certificação/escolaridade e formação profissional}

Todos os trabalhadores que não foram certificados receberam orientação e encaminhamento para diversos tipos de percursos educativos: ora para complementarem sua escolaridade, ora para realizarem cursos de qualificação profissional necessários para satisfazer os quesitos necessários à obtenção do certificado profissional, nas áreas em que se haviam submetidos à avaliação.

Houve uma grande diferença entre o grupo da construção civil e aquele da área metal-mecânica, no que diz respeito à escolaridade. O segundo grupo, apesar de possuir uma maior porcentagem de trabalhadores que haviam concluído o Ensino Médio, ao termino do processo de avaliação, apresenta uma grande defasagem em relação ao domínio de conhecimentos técnico-científicos atinentes ao setor metal-mecânico. Em vista disso, construiu-se de forma negociada - trabalhadores, sindicato e empresas - um acordo para organizar cursos de formação que abordassem conteúdos relativos a medidas, instrumentos de leitura e interpretação de desenhos técnicos. 


\section{Participação do Sindicato dos Metalúrgicos na Experiência Piloto}

Como se pode notar, a participação e o envolvimento do sindicato não só contribuiu para construção de referências conceituais e técnico-operacionais, como garantiu as condições necessárias para a efetiva participação dos trabalhadores interessados, negociando com as empresas: os tempos de dispensa para a participação nas atividades de formação e certificação; a autorização negociada para a realização das atividades iniciais de sensibilização no interior das próprias empresas, durante os horários de trabalho. Após o termino do processo de certificação, elaborou-se uma proposta de qualificação, com o objetivo de ofertar uma formação profissional para aqueles que precisam de uma complementação técnico-científica (por exemplo, conteúdos de matemática e desenho) para a obtenção do referido certificado profissional.

O sindicato ofereceu um formador (metalúrgico experiente) que participou das várias etapas do processo, desde o curso de segurança no trabalho (ministrado junto com outros companheiros do sindicato), como também das discussões para a construção e aplicação dos instrumentos de certificação.

Há que se ressaltar também a importância da participação do sindicato e dos próprios trabalhadores das empresas na escolha e montagem dos instrumentos de avaliação.

\section{Algumas considerações sobre os pontos fortes dessa experiência}

Essa experiência tinha por objetivo pôr à prova alguns dos referenciais teórico-políticos que nortearam a construção do Sistema Nacional de Certificação Profissional. Ainda que preliminar, possibilitou a verificação de algumas das hipóteses a respeito do modelo de certificação proposto.

\subsection{Avanços conceituais e metodológicos}

Os avanços no plano conceitual parecem-nos substantivos, pois se tratou de esboçar uma fundamentação teórica que fizesse um contraponto políticocultural com o modelo de competências, tão difundido pelos órgãos internacionais hegemônicos.

O modelo de certificação construído nessa proposta do MTE pauta-se numa perspectiva sócio-construtivista, que interpreta o desempenho e a proficiência profissional como resultante de itinerários e percursos que os trabalhadores(as) constroem e desenvolvem durante sua experiência de vida e de trabalho. Os contextos de vida e de trabalho representam os lugares da experiência e de saberes não estruturados, absorvidos e reconstruídos de modo não linear e ativo pelos(as) trabalhadores(as), configurando-se em uma 
complexa combinação de vários tipos de conhecimentos: estruturados (escolares), e de uma vasta gama de "saberes de experiência feitos", nas palavras de Paulo Freire (1992, p. 85), oriundos das aprendizagens de vida e dos contextos de trabalho. Trata-se, portanto, de um processo de construção/reconstrução contínuo de aquisição de saberes, representações, procedimentos necessários para fazer frente às situações e condições de trabalho, em geral suscetíveis de modificação, ao longo do tempo. Existem, portanto, no processo de construção da competência e desempenho profissional, dimensões de ordem psico-comportamental e sociocultural com recortes de gênero, etnia, classe, ético-política etc. Há dimensões de racionalidade e subjetividade, elementos de construção de identidades (individuais e coletivas).

Essa concepção ampliada de qualificação social e profissional contrastase com aquelas que "reduzem a qualificação ao domínio de habilidades e competências, de conhecimentos técnico-científicos particulares, a modelos e processos de reestruturação, gestão, qualidade total etc.".

Do ponto de vista metodológico, o modelo de certificação construído diferencia-se do modelo de competências, pois não foram usados normas e procedimentos baseados em perfis profissionais padronizados, fechados, elaborados na maioria das vezes sem a participação dos sujeitos que trabalham. Tratou-se de construir um modelo mais aberto, pautado numa lógica diferente. Não se procurou comparar o perfil e as capacidades de uma pessoa com um perfil Standard externo, mas sim apreender o percurso de construção, a partir de totalidades mais amplas e complexas, da multiplicidade de contextos em que foram geradas, desvelando aspectos e dimensões da trajetória profissional pouco conhecida e valorizada até pelo próprio sujeito interessado. Tratou-se, portanto, de um processo de reconstrução da trajetória profissional em sua historicidade, que resgatasse para o próprio sujeito do trabalho a importância de suas experiências, acúmulos e lacunas, de maneira que a certificação fosse entendida como um momento no interior do processo que poderia significar a redefinição de um percurso profissional, a busca de outras oportunidades de escolarização e formação, ou ainda a obtenção/mudança de emprego ou trabalho. Nesse sentido, adotaram-se estratégias, procedimentos e instrumentos de avaliação que, ao mesmo tempo permitissem identificar um padrão de desempenho satisfatório em relação ao perfil previamente traçado, mas que também fizessem emergir outras necessidades, características, lacunas, para reorientar os processos de qualificação, escolarização e orientação profissional.

Os resultados obtidos através da Experiência Piloto, ainda que numericamente pouco significativos, permitem mostrar que muitas das premissas 
acima podem ser concretamente operacionalizadas, não constituindo utopias educacionais e políticas. É possível construir um outro modelo de certificação baseado nas aprendizagens adquiridas nas experiências de vida e trabalho, com a mesma credibilidade, eficácia e eficiência daquele baseado no modelo de competências. Além disso, o modelo aqui esboçado possui um maior potencial de adaptação à heterogeneidade estrutural e sociocultural do mundo do trabalho e das peculiaridades regionais da sociedade brasileira.

\subsection{Dificuldades enfrentadas para a construção de um Sistema Nacional}

O projeto de Sistema Nacional de Certificação Profissional, desenhado durante o período 2002 a 2007, não chegou a ser oficializado, de modo que não foram criadas as condições jurídico-institucionais para sua construção e implementação. Algumas experiências pontuais e localizadas vêm sendo desenvolvidas baseadas nas premissas e diretrizes que serviram de inspiração, ao modelo que acabamos de apresentar, pois ainda há quem aposte no encaminhamento dialógico e negociado para a construção de políticas de qualificação e certificação profissional.

Contudo, a demora na regulamentação do Sistema tem dificultado a projeção de maior numero de experiências-piloto e a edificação de parâmetros jurídicos que regulem as práticas de certificação em todo o território nacional.

A interrupção do projeto compromete, a nosso ver, a implantação do Sistema Público de Emprego e a possibilidade de elaboração de políticas integradas de qualificação, certificação profissional e educação inicial e continuada de jovens e adultos, visando à construção de um Sistema de Educação Permanente.

\section{Referências}

BARRETTO, Ghione H. Recomendación 195 de OIT - Temas, enfoques y actores. Montevideo: CINTERFOR/OIT, 2005.

COSTA, Helio; CONCEIÇÃO, Martinho (Orgs.). Educação integral e sistema de reconhecimento e certificação educacional e profissional. São Paulo: CUT, 2005.

DUBAR, Claude. A sociologia do trabalho frente à qualificação e à competência. Revista Educação e Sociedade, Campinas: Cedes/Unicamp, n. 64, p. 87-104, 1998.

FAÏTA, Daniel; DONATO, Joseph. Langage, travail: entre compréhension et connaissance. In: SHWARTZ, Ives. Reconnaissances du travail: pour une approche ergologique. Paris: Presses Universitaires de France, 1997. p. 149-168.

FREIRE, Paulo. Pedagogia da esperança: um reencontro com a pedagogia do oprimido. 8. ed. Rio de Janeiro: Paz e Terra, 1992. 
FUNDAÇÃO FLORESTAN FERNANDES. Experiência Piloto de Certificação Profissional nos Setores da Construção Civil e Metal-Mecânica - Instrumentos de Diagnóstico e Avaliação para fins de Certificação, MTE/OIT, Diadema, 2005 (texto mimeografado).

INSTITUTO DE INFORMAÇÕES, ESTUDOS E PESQUISAS (Iiep). Avaliação da execução das experiências piloto. MTE/OIT, Brasília, 2005 (texto mimeografado).

. Sistematização dos resultados das experiências piloto. MTE/OIT, Brasília, 2006 (texto mimeografado).

. Instrumentos de certificação para o setor metal-mecânico. MTE/OIT, Brasília, 2006 (texto mimeografado).

. Instrumentos de certificação para o setor de construção civil. MTE/OIT, Brasília, 2006 (texto mimeografado).

LIMA, Antonio Almerico Biondi; LOPES, Fernando. Qualificação profissional: o papel dos sindicatos como instâncias de negociação, 2004 (texto mimeografado).

LIMA, Antonio Almerico Biondi. Negociação coletiva da qualificação profissional no local de trabalho e no estado. 2000. Tese (Doutorado) - Faced /UFBA, Salvador, Brasil, 2000.

MACHADO, Lucilia Regina de Souza. Qualificação do trabalho e relações sociais. In: FIDALGO, Fernando (Org.). Gestão do trabalho e formação do trabalhador. Belo Horizonte: Movimento de Cultura Marxista, 1996.

. A institucionalização da lógica das competências no Brasil. Revista Proposições, Campinas: FE/Unicamp, v. 13, n. 1, edição 37, p. 92-110, jan. / abr. 2002.

MANFREDI, Silvia Maria. Qualificação e educação: reconstruindo nexos e inter-relações. Brasília: MTE, SPPE, DEQ, 2005 (Construindo a Pedagogia do Trabalho, v. 1).

. Trabalho, qualificação e competência profissional: das dimensões conceituais e políticas. Revista Educação e Sociedade, Campinas: Cedes/Unicamp, n. 64, p. 13-50, 1998.

O Sistema nacional de certificação profissional: subsídios para reflexão e debate. Brasília: MTE, SPPE, DEQ, 2005 (Série Construindo Institucionalidades, v. 1).

. Metodologia de orientação profissional aplicada à certificação profissional. MTE/OIT, Brasília: 2006 (texto mimeografado).

. Do modelo de competências à valorização das "aprendizagens de experiência feitas". MTE/OIT, Brasília, 2007 (texto mimeografado).

MERTENS, Leonard. Competência laboral: sistemas, surgimento y modelos. Montevideo: OIT / CINTERFOR - Conocer, 1996.

ROPÉ, Françoise; TANGUY, Lucie (Orgs.). Saberes e competências: O uso de tais noções na escola e na empresa. Campinas: Papirus, 1997.

ROJAS, Eduardo. El saber obrero y la innovación en la empresa: las competencias y las calificaciones laborales. Montevideo: Cinterfor, 1999.

SCHWARTZ, Yves. De la qualification à la compétence. Société Française, n. 37, p. 1925, oct. / dec. 1990 (republié dans Éducation Permanente, Paris, n. 123, p. 125-137, 1995). 
SOUSA, Marcelo Álvares de. A Política Nacional de Certificação Profissional: por uma institucionalidade sistêmica, inclusiva participativa e eficiente. Brasília: MET/SPPE/DQ, 2004 (texto mimeografado).

STEFFEN, Ivo; BRÍGIDO, Raimundo; FREIRE, Lucienne. Certificação de Competências Profissionais - relatos de algumas experiências brasileiras. Brasília: MTE/OIT, 2002.

VARGAS, Fernando; BRIGIDO, Raimundo; STEFFEN, Ivo. Certificação de Competências Profissionais - Análise Qualitativa do Trabalho, Avaliação e Certificação de competências - Referenciais Metodológicos. Brasília: MTE/OIT, 2002.

TODESCHINI, Remígio. Desafios para a construção do sistema público de emprego, trabalho e renda. Brasília: MTE, SPPE, DEQ, 2005 (Construindo ações integradas, v. 1).

VERAS, Roberto de Oliveira. A qualificação profissional como política pública. Brasília: MTE, SPPE, DEQ, 2005 (Construindo institucionalidades, v. 3).

VILLAVICENCIO, Daniel. Por una definición de la calificación de los trabajadores. Texto apresentado no IV Congresso Espanhol de Sociologia entre os Mundos, Madri, 2426 de set. 1992.

ZARIFIAN, Philippe. Le modèle de la compétence. Paris: Editions Liaisons, 2001. . El modelo de competencia y los sistemas produtivos. Montevideo: Cinterfor, 1999. . O Modelo de competência e suas consequências sobre os ofícios profissionais. In: SEMINÁRIO INTERNACIONAL DE EDUCAÇÃO PROFISSIONAL, TRABALHO E COMPETÊNCIAS. 1998. Rio de Janeiro, Anais eletrônicos. Rio de Janeiro: CIET, Disponível em: <http: / / www.cinterfor.org.uy)>. Acesso em: 12 fev. 2007.

ZÚÑIGA, Fernando Vargas. Competencias clave y aprendizaje permanente - Tres miradas en América Latina y Caribe. Montevideo: Cinterfor, 2004. 


\section{A policy of professional certification oriented towards social inclusion Abstract}

This article contains the analysis of the recent experiences carried out by the Department of Professional Certification and Guidance of the Office of Public Policies for Labor, of the National Labor Ministry of Brazil (2003-2007) geared to create inclusive policies for professional qualification, certification and counseling. The model of certification that was developed was built in a participative and negotiated manner. Conceptually, it intends to be a counterpoint to certain hegemonic orientations. From a juridicalinstitutional viewpoint, it aimed to set up the National System of Professional Qualification. The project was organized according to an inclusive perspective, as it aimed to be, besides a mechanism for work accreditation, a paved avenue for entering/ returning to the formal system of education or to give access to continuing educational programs. The model was tested in two experimental professional categories. Keywords: Labor. Education. Qualification. Professional certification. Public policies.

\section{Une politique de certification professionnelle orientée vers l'inclusion sociale Résumé}

Cet article contient l'analyse des expériences récentes réalisées par le Département de la Certification et Orientation Professionnelle du Secrétariat de Politiques Publiques de l'Emploi du Ministère du Travail et de l'Emploi (2003-2007), visant la construction de politiques inclusives de qualification, certification et orientation professionnelle. Le modèle de certification développé a été construit de manière participative et négociée. Conceptuellement, il prétend être un contrepoint à quelques orientations hégémoniques. Du point de vue juridique-institutionnel, il a visé la construction du Système National de la Certification Professionnelle. Le projet s'est appuyé sur une perspective inclusive, puisqu'il prétendait être une passerelle d'entrée/retour au système scolaire formel ou d'insertion dans des parcours formatifs de nature continuée, en plus d'être un mécanisme de certification pour le travail. Le modèle élaboré a été vérifié avec deux catégories professionnelles.

Mots clefs : Travail. Éducation. Qualification. Certification professionnelle. Politiques publiques.

\section{Una política de certificación profesional orientada hacia la inclusión social Resumen}

Ese artículo contiene la análisis de las experiencias recientes realizadas por el Departamento de Certificación y Orientación Profesional de la Secretaria de Políticas Públicas de Empleo del MTE (2003-2007), vueltas para la construcción de políticas inclusivas de cualificación, certificación y orientación profesional. El modelo de certificación desarrollado fue construido de modo participativo y negociado. Conceptualmente, intenta ser un contrapunto a algunas orientaciones hegemónicas. Del punto de vista jurídico-institucional buscó construir el sistema nacional de certificación profesional. El proyecto se pautó en una perspectiva inclusiva, pues intentaba ser, además de un mecanismo de inscripción para el trabajo, una pasarela de ingreso/ retorno al sistema escolar formal o de naturaleza continuada. El modelo fue testado con dos categorías profesionales. Palabras clave: Trabajo. Educación. Cualificación. Certificación profesional. Políticas públicas. 